\title{
Perencanaan dan Pengendalian Persediaan Bahan Baku Benang dengan Lot Sizing Economic Order Quantity
}

\section{Sewings Raw Material's Inventory Planning and Control using Economic Order Quantity Lot Sizing}

\author{
Christian Lois ${ }^{1}$, Janny Rowena ${ }^{2}$, Hendy Tannady ${ }^{3 *}$ \\ ${ }^{1,3}$ Program Studi Teknik Industri, Universitas Bunda Mulia, Jl. Lodan Raya No. 2 Ancol, Jakarta Utara 14430, \\ Indonesia \\ ${ }^{2}$ Program Studi Manajemen, Universitas Bunda Mulia, Jl. Lodan Raya No. 2 Ancol, Jakarta Utara 14430, \\ Indonesia \\ *email: htannady@bundamulia.ac.id
}

Received: July 4, 2017; Revised: July 21, 2017; Accepted: August 7, 2017

\begin{abstract}
ABSTRAK
Objek penelitian ini adalah sistem persediaan pada sebuah perusahaan manufaktur dengan produk kaos kaki di daerah Tangerang, Banten. Jenis kaos kaki yang diproduksi adalah jenis kaos kaki putih polos, kaos kaki hitam, dan kaos kaki anak kecil. Penelitian ini bertujuan untuk mengetahui gambaran perencanaan dan pengendalian persediaan bahan baku benang dan mengetahui berapa jumlah bahan baku yang perlu disiapkan serta total biaya produksi yang dihasilkan dengan menerapkan metode Material Requirement Planning dari proses produksi. Dalam kegiatan produksinya, perusahaan menggunakan 4 bahan baku utama dalam pembuatan kaos kaki putih yaitu benang Polyester White, Spandex, Nylon serta Karet. Dalam satu hari, produksi menghasilkan 3 lusin kaos kaki. Bahan baku yang digunakan adalah 1 cone benang untuk 2.5 lusin. Maka untuk menghasilkan 3 lusin kaos kaki dalam sehari, diperlukan 1.2 cone benang. Dari hasil analisis tersebut, diketahui bahwa biaya pemesanan adalah Rp.28000 per pesan dan biaya penyimpanan adalah Rp.2000 per unit per tahun. Dengan demikian nilai kebutuhan ekonomis atau Economic Order Quantity yang dihasilkan adalah 157 unit. Maka, untuk bahan baku benang Polyester White (75\%) membutuhkan 47.1 cone, benang Spandex (15\%) membutuhkan 9.42 cone, benang Nylon (5\%) dan benang Karet (5\%) sama-sama membutuhkan 3.14 cone. Biaya set up adalah Rp.156586 sedangkan biaya penyimpanan adalah Rp.157000 sehingga total biaya yang dihasilkan adalah Rp.313586.
\end{abstract}

Kata Kunci: Kaos Kaki, Material Requirement Planning, Economic Order Quantity

\begin{abstract}
The object of this study is the inventory system of manufacturing companies with sock products in Tangerang, Banten. Types of socks produced are plain white socks, black socks, and small socks. This study aims to determine the description of the planning and control of raw material inventory and find out how much raw materials to be prepared as well as the total cost of production produced by applying the method of Material Requirement Planning from the production process. In its production activities, the company uses 4 main raw materials making white socks namely Polyester White yarn, Spandex, Nylon, and Rubber. In one day, production produces 3 dozen socks. The raw materials used are 1 cone yarn for 2.5 dozen. So to produce 3 dozen socks a day, it takes 1.2 cone threads. From the analysis, it is known that the booking fee is Rp.28000 per message and the storage fee is Rp.2000 per unit per year. Thus the value of economic needs or Economic Order Quantity generated is 157 units. Thus, for Polyester White yarn material (75\%) requires 47.1 cones, Spandex yarn (15\%) requires 9,42 cones, nylon yarn (5\%) and rubber yarn $(5 \%)$ equally require 3.14 cone. Set up fee Rp.156586 while the storage fee Rp.157000 so the total cost Rp.313586.
\end{abstract}

Keywords: Socks, Material Requirement Planning, Economic Quantity 


\section{PENDAHULUAN}

Pertumbuhan penduduk di Indonesia sangat tinggi. Menurut data statistik, Indonesia menempati urutan ke-4 penduduk terpadat di dunia. Dengan tingginya tingkat kepadatan tersebut, membuat tingkat kebutuhan pokok penduduk baik dalam segi sandang, pangan dan papan juga semakin tinggi. Tingginya kebutuhan tersebut, telah menciptakan peluang pasar dan industri baik industri besar maupun industri kecil yang menjangkau segala aspek kebutuhan masyarakat termasuk kebutuhan sandang atau pakaian yang kini tidak selalu berbicara pada baju dan celana tetapi menjangkau ke ranah lebih luas seperti jaket, selimut, bahkan kaos kaki.

Objek penelitian ini adalah sistem persediaan pada sebuah perusahaan manufaktur dengan produk kaos kaki di daerah Tangerang, Banten. Jenis kaos kaki yang diproduksi adalah jenis kaos kaki putih polos, jenis kaos kaki hitam, dan jenis kaos kaki anak kecil. Kegiatan kunci pada perusahaan melingkupi kegiatan produksi, penyimpanan barang hingga persediaan bahan baku utama yaitu benang.

Saat ini perusahaan memiliki permasalahan sistem pengendalian persediaan bahan baku yang tidak terstruktur dan terjadwal. Metode yang digunakan oleh perusahaan adalah menggunakan perhitungan konvensional tanpa melakukan suatu peramalan atau perencanaan yang baik, sehingga memerlukan suatu metode yang dapat menangani masalah perencanaan bahan baku benang.

Menurut Bhattacharyya dan Sengupta (2011), bahan baku merupakan salah satu komponen penting dalam sistem produksi yang perlu diperhatikan untuk kelancaran suatu produksi. Suatu perusahaan perlu merencanakan pembelian dan melakukan kontrol bahan baku untuk mengendalikan biaya bahan baku. Untuk mengatasi permasalahan perencanaan persediaan bahan baku, metode yang dapat digunakan adalah metode Material Requirement Planning (MRP) dimana metode ini merupakan metode perencanaan dan penjadwalan kebutuhan bahan baku produksi yang dapat mengatasi masalah-masalah kompleks yang timbul dalam persediaan sehingga dapat memberikan beberapa keuntungan seperti tingkat persediaan yang lebih rendah, ketepatan jadwal produksi dan secara langsung berdampak pada biaya produksi. Dalam sistem MRP, terdapat tahapan penentuan ukuran pemesanan (lot sizing). Pemakaian model lot sizing yang tepat akan sangat mempengaruhi efektivitas perencanaan kebutuhan bahan (Kristiana, 2008) salah satunya dengan metode Economic Order Quantity (EOQ) yang digunakan untuk merencanakan pembelian persediaan bahan baku yang ekonomis, di dasarkan pada pengaruh biaya penyimpanan dan pemesanan.

Penelitian ini dilakukan berdasarkan data penjualan bulan Maret 2016 hingga bulan Februari 2017. Maka dari itu, peramalan permintaan dilakukan untuk bulan Maret 2017 hingga Februari 2018. Perencanaan bahan baku benang hanya fokus pada benang penyusun kaos kaki putih polos. Pada penelitian ini, pemasok diasumsikan dapat memenuhi permintaan sesuai dengan jumlah yang di butuhkan. Harga bahan baku dan biaya yang terkait dalam perhitungan diasumsikan tidak mengalami perubahan.

Menurut Schroeder (2000), persediaan adalah stok bahan yang digunakan untuk memudahkan produksi atau untuk memuaskan permintaan pelanggan yang secara khusus meliputi barang bahan baku, bahan setengah jadi dan barang jadi. Persediaan memiliki tujuan yaitu berlindung dari ketidakpastian, memungkinkan produksi dan pembelian ekonomis, mengatasi perubahan permintaan atau penawaran, dan menyediakan transit. Menurut Heizer dan Render (2001), peramalan adalah seni dan ilmu memprediksi peristiwa masa depan yang memerlukan data historis dan memproyeksikannya ke masa depan dengan beberapa bentuk model matematis. Bisa jadi berupa prediksi subjekstif atau intuitif, dan bisa mencakup kombinasi model matematis yang disesuaikan dengan penilaian yang baik. Di dalam pemenuhan permintaan pasar yang 
cenderung mengalami naik turun tetapi stabil, peramalan yang dapat digunakan adalah metode exponential smoothing yang dihitung dengan persamaan (1).

$F_{t}=F_{t-1}+\alpha\left(A_{t-1}-F_{t-1}\right)$

dimana:

$F_{t} \quad=$ Data peramalan periode $t$

$F_{t-1} \quad=$ Data peramalan sebelum periode $t$

$A_{t-1} \quad=$ Data actual periode $t$

$\alpha=$ Konstanta perataan antara 0-1

Menurut Herjanto, (1999), Jadwal Produksi Induk (MPS) adalah gambaran atas periode perencanaan dari suatu permintaan termasuk peramalan, backlog, rencana suplai, persediaan akhir dan kuantitas yang dijanjikan tersedia (available to promise). MPS disusun berdasarkan perencanaan produksi agregat dan kunci penghubung dalam perencanaan dan pengendalian produksi. Sedangkan MRP adalah suatu sistem perencanaan dan penjadwalan kebutuhan material untuk produksi yang memerlukan beberapa tahapan proses atau fase. MRP merupakan suatu rencana produksi untuk sejumlah produk jadi yang diterjemahkan ke dalam masing-masing komponen yang dibutuhkan dengan waktu tenggang, sehingga ditentukan kapan dan berapa banyak bahan yang dipesan untuk masing-masing komponen produk yang dibuat (Rangkuti, 2004). Heizer dan Render (2011) menjelaskan bahwa terdapat beberapa proses perhitungan MRP:

1. Kebutuhan Kotor, menunjukkan permintaan total untuk sebuah barang (setelah dikurangi persediaan di tangan dan tagihan ter jadwal) termasuk kapan harus dipesan dari pemasok, atau ketika produksi harus dimulai untuk memenuhi permintaan pada tanggal tertentu.

2. Kebutuhan Bersih, hasil dari penyesuaian kebutuhan kotor terhadap persediaan di tangan yang telah siap dan penerimaan pesanan terencana.

3. Penerimaan pesanan terencana, jumlah yang rencananya akan diterima di masa depan.
4. Pengiriman pesanan terencana, tanggal Jadwal untuk melepaskan suatu pesanan.

Keluaran dari sistem MRP berupa rencana pemesanan atau rencana produksi yang dibuat atas dasar lead time yaitu tentang waktu sejak barang dipesan sampai barang diterima, atau apabila barang dibuat maka lead time item yang dibuat adalah waktu sejak item perintah pembuatan sampai dengan item selesai diproses (Baroto, 2002). Model lot-sizing merupakan penentuan jumlah barang yang harus di order dimana mementuksn seberapa banyak barang yang diperlukan mengimbangi peramalan permintaan yang ada. Menurut Handoko (1999), ketika peramalan permintaan yang cenderung konstan dan tidak mengalami peningkatan dan penurunan yang fluktuatif setiap periode nya, serta harga per unit dan biaya penyimpanan ataupun pemesanan adalah konstan, maka digunakan teknik lotting metode Economic Order Quantity. Metode ini menggambarkan pemesanan bahan baku yang ekonomis yang didasarkan pada biaya persediaan. Persamaan (2) adalah rumus matematis untuk metode EOQ.

$$
E O Q=\sqrt{\frac{2 \cdot D \cdot S}{H}}
$$

dimana:

$D \quad=$ rata-rata kebutuhan dalam satu periode

$S \quad=$ biaya pemesanan

$H$ = biaya simpan/unit dalam suatu periode tertentu

\section{METODOLOGI}

Penelitian ini merupakan penelitian deskriptif, yaitu penelitian yang berkenaan dengan fakta, keadaan, variabel, dan fenomena yang terjadi saat penelitian berlangsung dan menyajikannya apa adanya (Subana dan Sudrajat, 2001). Objek penelitian yang dianalisis adalah mengetahui jumlah permintaan persediaan bahan baku yang digunakan untuk menganalisis penerapan MRP yang diawali dengan menganalisis jadwal produksi induk, struktur produk dan daftar 
kebutuhan bahan, serta diakhiri dengan menganalisis besarnya jumlah pesanan optimal untuk setiap bahan baku. Sumber data yang digunakan adalah data primer dan data sekunder. Data primer yaitu data yang mengacu pada informasi yang diperoleh dari tangan pertama yang berkaitan dengan variabel minat untuk tujuan spesifik studi. Data-data tersebut meliputi aliran proses produksi, biaya pesan dan biaya penyimpanan, lead time pemesanan bahan baku. Sedangkan data sekunder yaitu data yang mengacu pada informasi yang dikumpulkan dari sumber yang telah ada, seperti artikel, internet, jurnal, dan dokumentasi perusahaan. Data-data tersebut meliputi Bill of Materials (BOM), struktur produk, data permintaan produk dan data aktual persediaan (Sekaran, 2000).

Metode pengumpulan data dalam penelitian ini dilakukan dengan cara sebagai berikut:

1. Wawancara, yaitu metode pengumpulan data dengan cara mengadakan tanya jawab secara langsung dengan pimpinan atau karyawan sesuai dengan objek yang diteliti

2. Observasi, yaitu merupakan metode pengumpulan data dengan cara melakukan pengamatan langsung dan mengambil langsung terhadap objek penelitian yang diamati

3. Dokumentasi, yaitu metode pengumpulan data dengan mengutip dari dokumen perusahaan.

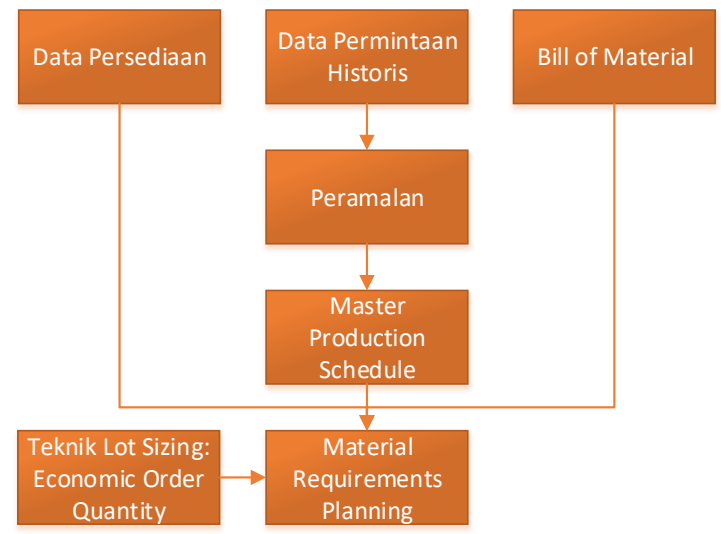

Gambar 1. Langkah Pengolahan Data

\section{HASIL DAN PEMBAHASAN}

Dalam menjalankan kegiatan produksi kaos kaki, perusahaan sangat tergantung pada bahan baku guna mengatur dan menjalankan proses produksi. Pembuatan kaos kaki membutuhkan bahan baku yang berupa beberapa jenis benang. perusahaan memproduksi kaos kaki putih yang mempunyai 4 (empat) bahan baku yaitu benang Polyester 150 White, benang Spandex, benang Nylon dan benang karet. Tabel 1 menunjukkan konversi produksi atas komposisi bahan baku dan bahan penyusun material.

Tabel 1. Konversi Produksi Bahan Baku.

\begin{tabular}{ccc}
\hline Bahan Baku & 1 Cone & 2.5 Lusin \\
\hline Produksi & 1.2 Cone & 3 Lusin \\
\hline
\end{tabular}

Dari informasi bahan baku produksi pada Gambar 2, maka kegiatan produksi dapat dijalankan dengan baik jika perusahaan memiliki persediaan dari keempat bahan baku pada saat terdapat permintaan. Dalam pelaksanan kegiatan produksi, perusahaan melakukan pencatatan data penjualan sebagai data histori penjualan. Pada penelitian ini, data tersebut dipakai untuk melakukan peramalan penjualan untuk periode selanjutnya. Tabel 2 menampilkan data penjualan selama Maret 2016 hingga Februari 2017. 


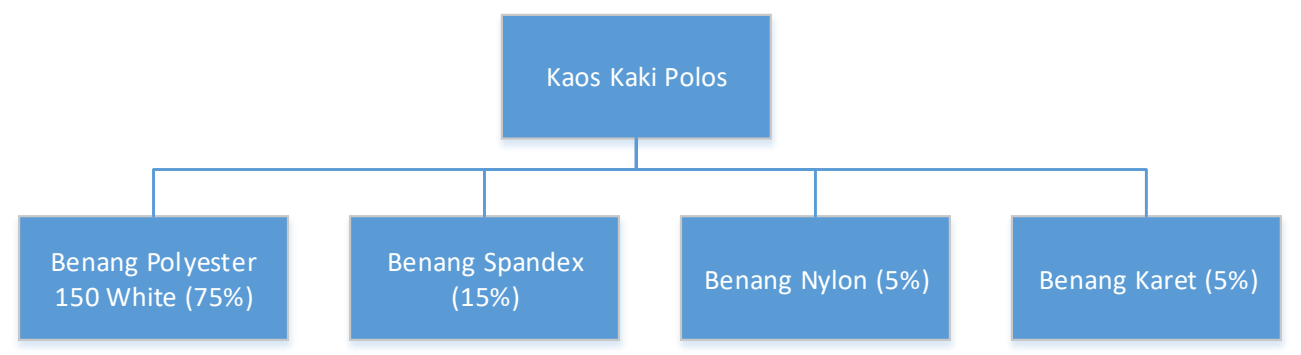

Gambar 2. Struktur Produk Kaos Kaki Polos.

Tabel 2. Data Penjualan per Bulan Periode Maret 2016-Februari 2017

\begin{tabular}{lc}
\hline Periode (Bulan) & Penjualan (Lusin per Bulan) \\
\hline Maret 2016 & 66 \\
April 2016 & 70 \\
Mei 2016 & 76 \\
Juni 2016 & 78 \\
Juli 2016 & 76 \\
Agustus 2016 & 74 \\
September 2016 & 78 \\
Oktober 2016 & 72 \\
November 2016 & 74 \\
Desember 2016 & 68 \\
Januari 2017 & 70 \\
Februari 2017 & 66 \\
\hline
\end{tabular}

Berdasarkan data penjualan dapat dianalisis bahwa data tersebut merupakan data yang bersifat kuantitatif yang memiliki pola tren yang naik turun tetapi tidak fluktuatif dan stabil. Dari tipe data diatas, maka perlu dilakukan peramalan data penjualan dengan menggunakan metode peramalan Exponential Smoothing seperti pada Tabel 3.

Peramalan penjualan dilakukan untuk mengetahui jumlah perkiraan produksi pada periode selanjutnya. Peramalan tersebut berhubungan dengan metode perencanaan yang dipakai. Metode EOQ menggambarkan pemesanan bahan baku yang ekonomis yang didasarkan pada biaya biaya terperinci seperti biaya pemesanan dan biaya penyimpanan. Tabel 4 adalah rincian biaya penyimpanan dan penyimpanan, serta perhitungan EOQ.

Tabel 3. Data Peramalan Penjualan Metode Exponential Smoothing

\begin{tabular}{lclcc}
\hline Periode (Bulan) & Penjualan (Lusin per Bulan) & Periode (Bulan) & Peramalan $(\alpha=0.5)$ & Round Up \\
\hline Maret 2016 & 66 & Maret 2017 & 71.00000 & 71 \\
April 2016 & 70 & April 2017 & 68.50000 & 69 \\
Mei 2016 & 76 & Mei 2017 & 69.25000 & 70 \\
Juni 2016 & 78 & Juni 2017 & 72.62500 & 73 \\
Juli 2016 & 76 & Juli 2017 & 75.31250 & 76 \\
Agustus 2016 & 74 & Agustus 2017 & 75.65625 & 76 \\
September 2016 & 78 & September 2017 & 74.82812 & 75 \\
Oktober 2016 & 72 & Oktober 2017 & 76.41406 & 77 \\
November 2016 & 74 & November 2017 & 74.20703 & 75 \\
Desember 2016 & 68 & Desember 2017 & 74.10351 & 75 \\
Januari 2017 & 70 & Januari 2018 & 71.05175 & 72 \\
Februari 2017 & 66 & Februari 2018 & 70.52587 & 71 \\
Total & & & 878 \\
\hline
\end{tabular}

Tabel 4. Data Biaya Pemesanan dan Biaya Penyimpanan.

\begin{tabular}{lrlr}
\hline Set Up Cost (Rupiah Per Tiap Pesanan) & & Holding Cost (Rupiah / 1 Unit dalam Satu tahun) & \\
\hline Biaya Telepon & 2000 & Biaya Penyimpanan & 2000 \\
Biaya Administrasi & 1000 & & \\
Biaya Ongkos Kirim & 25000 & & 2000 \\
Total & 28000 & Total & \\
\hline
\end{tabular}




$$
\begin{gathered}
E O Q=\sqrt{\frac{2.878 .28000}{2000}} \\
E O Q=156.792857=157
\end{gathered}
$$

Dengan nilai $Q$ berjumlah 157, maka frekuensi pemesanan dilakukan sebanyak $f$ sejumlah:

$f=\frac{D}{E O Q}=\frac{878}{157}=5.59$

Setelah mengetahui jumlah kebutuhan optimal bahan baku benang sekali pesan adalah 157, maka disusun tabel perencanaan bahan baku MRP yang dibuat untuk bulan Maret 2017 sampai Februari 2018, terdiri atas 12 bulan dengan proses lotting yang digunakan menggunakan teknik EOQ serta lead time yang digunakan adalah 1 bulan.

Konsep MRP melakukan penjadwalan pemesanan agar material atau bahan baku datang tepat pada waktunya, sehingga proses produksi dapat berjalan lancar, sehingga perusahaan mengetahui spesifikasi, waktu dan jumlah bahan baku secara tepat dan efisien. Dengan demikian, hasil perhitungan MRP dapat dijadikan bahan acuan dan pertimbangan pengambilan keputusan yang tepat dalam melakukan perencanaan dan pengendalian persediaan bahan baku guna kelancaran proses produksi dengan keputusan yang efisien dari segi biaya serta ketepatan waktu sehingga kepuasan pelanggan dapat terpenuhi dan perusahaan memperoleh keuntungan peningkatan laba. Tabel 6 merupakan tabel MRP tiap bahan baku yang disesuaikan dengan Bill of Material dan lot sizing berupa EOQ.

Dengan mengetahui penjadwalan MRP produk kaos kaki polos dengan acuan peramalan penjualan selama satu tahun, maka kebutuhan bahan baku penyusun produk kaos kaki tersebut disesuaikan antara jumlah produksi selama satu hari (daily production), jumlah bahan baku dalam produksi harian, dan persentasi komponen tiap bahan baku.

Tabel 5. Jadwal Induk Produksi (MPS)

\begin{tabular}{ccccccccccccc}
\hline Periode & 1 & 2 & 3 & 4 & 5 & 6 & 7 & 8 & 9 & 10 & 11 & 12 \\
\hline Peramalan/Target & 71 & 69 & 70 & 73 & 76 & 76 & 75 & 77 & 75 & 75 & 72 & 71 \\
\hline
\end{tabular}

Keterangan: disesuaikan dengan peramalan.

Tabel 6. Material Requirement Planning (MRP) Produk Kaos Kaki Putih Polos.

\begin{tabular}{lcccccccccccccc}
\hline \multicolumn{1}{c}{ Month } & P. Due & 1 & 2 & 3 & 4 & 5 & 6 & 7 & 8 & 9 & 10 & 11 & 12 & Next \\
\hline Gross Requirements & & 71 & 69 & 70 & 73 & 76 & 76 & 75 & 77 & 75 & 75 & 72 & 71 & \\
Schedule Receipts & & & & & & & & & & & & & & \\
Projected On-Hand & 5 & 5 & 91 & 22 & 109 & 36 & 117 & 41 & 123 & 46 & 128 & 53 & 138 & 67 \\
Net Requirements & & 66 & & 48 & & 40 & & 34 & & 29 & & 19 & & \\
Planned Order Receipts & & 157 & & 157 & & 157 & & 157 & & 157 & & 157 & \\
Planned Order Release & 157 & & 157 & & 157 & & 157 & & 157 & & 157 & & \\
\hline
\end{tabular}

Keterangan: Lot sizing = EOQ dan Lead Time $=1$ bulan

Tabel 7. Konversi dan penyesuaian total bahan baku sebenarnya.

\begin{tabular}{lcccccc}
\hline Bahan Baku & Komponen & $\begin{array}{c}\text { Q } \\
\text { (Lusin) }\end{array}$ & Produksi/Hari & $\begin{array}{c}\text { Bahan } \\
\text { Baku/Hari }\end{array}$ & $\begin{array}{c}\text { Bahan } \\
\text { Baku Total }\end{array}$ & $\begin{array}{c}\text { Bahan Baku/ } \\
\text { Komponen }\end{array}$ \\
\hline Polyester 150 & $75 \%$ & 157 & 3 Lusin & 1.2 Cone & 62.8 & 47.1 \\
White & $15 \%$ & 157 & 3 Lusin & 1.2 Cone & 62.8 & 9.42 \\
Spandex & $5 \%$ & 157 & 3 Lusin & 1.2 Cone & 62.8 & 3.14 \\
Nylon & & & & \\
\hline
\end{tabular}


Berdasarkan EOQ, maka penjadwalan yang direncanakan seperti perhitungan diatas menimbulkan total biaya yang dikeluarkan. Total biaya tersebut dipengaruhi oleh biaya set up dan biaya penyimpanan yang dipakai.

$Q=157$

Setup Cost $=\frac{D . S}{Q}=\frac{878.28000}{157}=156586$

Holding Cost $=\frac{Q . H}{2}=\frac{157.2000}{2}$ $=157000$

Total Cost $=156586+157000=313586$

\section{KESIMPULAN}

Secara keseluruhan penerapan MRP telah memberikan gambaran mengenai penjadwalan persediaan bahan baku mulai dari pengolahan data dengan peramalan, membuat perencanaan penjadwalan per tiap bulan nya, hingga mengetahui total biaya yang dapat membantu kelancaran proses produksi sehingga proses produksi berjalan efisien.

Penentuan jumlah kebutuhan bahan baku disesuaikan dengan struktur produk dan metode penentuan ukuran lot pemesanan bahan baku disesuaikan dengan karakteristik data, naik turunnya persebaran data, serta biaya penyimpanan dan biaya penyetelan bahan baku. Perusahaan dapat melakukan pesanan terjadwal berdasarkan lembar hasil perhitungan MRP sehingga perusahaan dapat melakukan pemesanan tepat waktu dan terjadwal sesuai dengan kebutuhan produksi.

Struktur produk kaos kaki polos terdiri atas 4 jenis benang yang berada pada 1 level yaitu benang Polyester White (75\%), benang Spandex (15\%), benang Nylon (5\%) dan benang Karet (5\%). Data penjualan perusahaan selama satu tahun (Maret 2015-Februari 2016) dijadikan acuan untuk peramalan penjualan satu tahun kedepan (Maret 2017-Februari 2018). Peramalan menggunakan metode
Exponential Smoothing dengan $\alpha=0.5$ sehingga hasil peramalan diproyeksikan sebagai dasar pembuatan penjadwalan persediaan MRP. Lot sizing yang digunakan adalah dengan menggunakan metode EOQ yang didasarkan pada biaya pemesanan sejumlah Rp.28000 per pesan dan biaya penyimpanan sejumlah Rp.2000 per unit per tahun. Nilai EOQ yang dihasilkan berjumlah 157.

Tabel perencanaan bahan baku MRP yang dibuat untuk bulan Maret 2017 sampai Februari 2018 terdiri atas 12 bulan dengan proses lotting yang digunakan menggunakan teknik EOQ serta lead time yang digunakan adalah 1 bulan. Setelah itu, dilakukan konversi dan penyesuaian terhadap jumlah kuantitas barang yang dihasilkan terhadap jumlah cone yang diperlukan untuk menyediakan bahan baku tersebut selama satu bulan kedepan. Untuk bahan baku benang Polyester White (75\%) membutuhkan 47.1 cone, benang Spandex (15\%) membutuhkan 9.42 cone, benang Nylon $(5 \%)$ dan benang Karet $(5 \%)$ sama sama membutuhkan 3.14 cone.

Total biaya yang dikeluarkan dipengaruhi oleh biaya set up cost dan biaya penyimpanan yang dipakai. Biaya set up yang dikeluarkan adalah Rp.156586 sedangkan biaya penyimpanan yang dikeluarkan adalah Rp.157000 sehingga total biaya yang dihasilkan adalah Rp.313586.

Metode peramalan Exponential Smoothing dapat dijadikan sebagai metode peramalan yang baik untuk memberi acuan pembuatan penjadwalan bahan baku atau MRP. Dalam melakukan pengelolahan terhadap persediaan bahan baku, metode MRP dapat diterapkan dengan tepat karena hasil yang diberikan berupa gambaran kapan perusahaan melakukan pembelian dan pemesanan, serta kuantitas produk yang ekonomis untuk dapat memberi pengehematan terhadap biaya produksi.

\section{DAFTAR PUSTAKA}

Baroto, T. (2002). Perencanaan dan Pengendalian Produksi. Jakarta: Gahlia Indonesia. Hal 80. Bhattacharyya, D., dan Sengupta, N. (2011). Management Accounting. Dorling Kindersley. 
Handoko, H. T. (1999). Dasar-dasar Manajemen Produksi dan Operasi. Edisi 7. Yogyakarta: BPFE. Heizer, J., dan Render, B. (2001). Prinsip-Prinsip Manajemen Operasi. Jakarta: Salemba Empat.

Heizer, J., dan Render, B. (2011). Manajemen Operasi. Terjemahan. Buku 2. Edisi 9. Salemba Empat: Jakarta.

Herjanto, E. (1999). Manajemen Produksi dan Operasi. Jakarta. Edisi kedua. PT. Gramedia Widiasarana Indonesia.

Kristiana, I. (2008). "Program Bantu Perencanaan dan Pengendalian Persediaan Bahan Baku Pada Proses Produksi Toner". Jurnal Informatika. Vol. 4 No. 2; hal 37-38.

Rangkuti, F. (2004). Manajemen Persediaan Aplikasi di Bidang Bisnis. PT Raja Grafindo Persada: Jakarta.

Schroeder, Roger G. (2000). Operations Management: Contemporary Concept and Cases. McGrawHill: New York.

Sekaran, U. (2000). Metode Penelitian Untuk Bisnis. Edisi Empat. Jakarta: Salemba Empat.

Subana, M. dan Sudrajat. (2001). Dasar-dasar Penelitian Ilmiah. Bandung: CV. Pustaka Pelajar. 